\title{
I. The electricity of atmospheric precipitation
}

\section{G.C. Simpson D.Sc.}

To cite this article: G.C. Simpson D.Sc. (1915) I. The electricity of atmospheric precipitation , Philosophical Magazine Series 6, 30:175, 1-12, DOI: 10.1080/14786440708635370

To link to this article: http://dx.doi.org/10.1080/14786440708635370

册 Published online: 08 Apr 2009.

Submit your article to this journal 준

Џll Article views: 2

Q View related articles $\square$

Citing articles: 6 View citing articles $\sqsubset$ 
LONDON, EDINBURGH, aND DUBLIN

\title{
PHILOSOPHICAL MAGAZIiNE
}

\author{
AND \\ JOURNAL OF SCIENCE.
}

[SIXTH SERIES.]

JULY 1915.

I. The Electricity of Atmospheric Precipitation. $B y$ G. O. SImpson, D.Sc.*

T $N$ recent years a great deal of work has been done with the object of determining the electrical state of atmospheric precipitation. The results have shown that the whole subject is a complicated one, and different observers do not agree in detail. There are, however, a few outstanding results which may now be taken as established, and it appears desirable to revise our ideas in the light of these new facts.

The following are the results which may be taken as having been substantiated by all recent observers $\dagger$ :-

\section{A. Non-thunderstorm Rain. (Ger. Landregen.)}

(1) Rain is sometimes positively and sometimes negatively charged $\ddagger$.

(2) About 90 per cent. of the rain is positively charged.

(3) The normal potential gradient is nearly always reversed during the rain.

* Communicated by the Author.

$\uparrow$ I do not propose to discuss the results of individual observers, but give as an appendix a list of all the workers in this subject with references to their publications.

† In all probability rain has always some charge and uncharged rain practically never occurs; but this cannot be stated with certainty until more delicate methods of observation are devised.

Phil. Mag. S. 6. Vol. 30. No. 175. July 1915. 
B. Thunderstorm precipitation.

(4) The precipitation is sometimes positively and sometimes negatively charged.

(5) More positive than negative electricity is brought down by the precipitation.

(6) The charges per unit mass of the precipitation and the vertical electrical currents produced by its fall are much larger than with non-thunderstorm rain.

(7) The potential gradient undergoes large and rapid changes of sign, and on the whole the potential gradient is more often reversed than not.

\section{Snow.}

(8) Snow is sometimes positively and sometimes negatively charged.

(9) In Simla positive electricity was in excess, while in Potsdam an excess of negative electricity was observed.

(10) A given weight of snow may be more highly charged than the same amount of rain, even in a thunderstorm.

(11) High values of the potential gradient, both positive and negative, occur during snowfall.

In the above $I$ have only stated results about which there is no difference of opinion; there are many others which are almost as certainly true, but as there is still some doubt they have been excluded.

So far as I know there are at present only two theories seriously put forward to account for the electricity of precipitation.

(A) The "influence" theory, first put forward by EIster and Geitel in $1885^{*}$, and revised by them in $1913 \dagger$.

(B) The "breaking drop" theory, put forward by the writer in $1909 \ddagger$ to explain the origin of electricity in thunderstorms.

I propose to consider each of these theories in the light of the established facts detailed above.

* Elster \& Geitel, Wied. Ann. xxv. pp. 123-124 (1885).

† Elster \& Geitel, Phys. Zeit. xiv. pp. 1287-1292 (1913).

$\ddagger$ Simpson, Phil. Trans. Roy. Soc. A. ccix. pp. 379-413 (1909). 


\section{A. Elster and Geitel's "Isfluence" Theory.}

The influence theory is based on what Elster and Geitel consider to be two facts :

(a) That small drops, in particular cloud particles, rebound from large drops without uniting with them;

(b) That although the small drops do not unite with the larger ones, electrical contact takes place.

Before going further it is necessary to examine these two premises, for it appears to me that they are not sufficiently well established to form the foundation of an important theory.

There can be little doubt that $(a)$ is true for pure uncharged water. Every one who has rowed on a river of clear water, or watched the drops falling into the basin of a fountain, will have seen small drops running on the surface for an appreciable time before they are absorbed. On the other hand, the great effect of an electrical charge in causing water-drops to unite has been observed by most physicists since it was first pointed out by Lord Rayleigh in $1879^{*}$. In a thunderstorm the drops are so highly charged relatively to one another that it is difficult to believe that there can be any large amount of impact without the drops uniting more or less completely. Indeed most writers have used this fact to account for the dark colour of the clouds and the heavy rain associated with thunderstorms.

The second foundation of the theory, that electrical contact takes place although the drops do not unite, is based on experiments made by Elster and Geitel in 1885. As these experiments have never been repeated, while the results have been accepted without question for thirty years, it seems desirable to examine them in the light of modern knowledge.

The experiments were shortly described by Elster and Geitel $\dagger$, and on account of their importance a literal translation is given here.

"The following method was used to prove that small water-drops can come into electrical contact with a large water surface without uniting with it.

"The metal nozzle of a "sprayer' was directed at an angle towards an insulated water surface which was connected to a Thomson quadrant electrometer. Over the

* Rayleigh, Proc. Roy. Soc. xxviii. p. 406 (1879).

$\dagger$ Elster \& Geitel, Wied. Ann. xxv. p. 129 (1885).

$\mathrm{B} 2$ 
nozzle a cylindrical metal tube, $1 \frac{1}{2} \mathrm{~cm}$. wide, was fixed so that the orifice of the sprayer was in the middle of the tube. The sprayer and tube were connected to earth, thus preventing any electrical field acting on the nozzle and so charging the drops by influence.

"By this arrangement a large proportion of the spray was reflected from the water surface. Above the spraycloud was suspended an insulated sphere, of $2 \mathrm{~cm}$. radius, which could be connected at will to the positive or negative pole of a Zamboni pile having 2000 pairs of plates. It was then found that when the sprayer was in action the insulated vessel containing the reflecting water surface took on a charge which was of the same sign as the charge on the metal sphere. The charge was so large that it could not be read by the telescope and scale. At the same time the spray was found to carry a charge of the opposite sign. From the latter fact we see that there was no transference of charge from sphere to surface through the spray-cloud. The spray particles bouncing from the water surface acted exactly like the drops in a 'Thompson 'water dropper' and the vessel containing the water surface like the collector itself. This, however, was only possible if the bouncing drops came into electrical contact with the water surface."

Elster and Geitel's explanation of this experiment was the only one possible in 1885 , but a much more reasonable one is obvious now. As shown by Eve * and others, when water is sprayed in the manner described the air in the blast is bighly ionized. Thus in the experiment the fine water particles were carried along in a stream of ionized air. When this stream came into the strong electrical field between the positively charged sphere and the water surface, the positive ions were driven into the latter, and part of the excess of negative ions became attached to the spray particles. The reverse happened when the sphere was charged negatively. This explanation accounts for the facts without supposing any rebounding of water-drops. In fact the result would have been the same if all the drops could have been removed before the air-blast came into contact with the water surface.

When one considers that the cause of a drop bounding from a water surface is the film of air between the two, it is difficult to see how electrical contact could take place until this layer has been removed and the two surfaces joined up. In this connexion it may be pointed out that C. R. Englund +

* Eve, Phil. Mag. [6] xiv. p. 382 (1007).

† Englund, Phil. Mag. xxrii. pp. 457-458, March 1914. 
found that there was perfect insulation between two conductors only half a sodium wave-length apart.

A theory built on such questionable foundations would not be considered strong even if it appeared capable of explaining the phenomena, but it will now be shown that, granting these premises of Fister and Geitel, the theory tails to explain the chief electrical phenomena during precipitation.

The influence theory as revised in 1913 is as follows :-

Consider a drop of water falling through the atmosphere. It is then in an electrical field and in consequence becomes electrically polarized. If we assume the earth's normal field, then the drop will have a positive charge on its under half and a negative charge on its upper half. As this drop falls through a cloud which is raining it will constantly strike, on its under side, cloud particles and smaller drops. These small drops make electrical contact, take on to themselves part of the induced positive charge from the large drop, and then rebound. In consequence the large drop becomes negatively charged and the cloud particles positively charged.

Now the most important point to notice in this theory is that with any given field the rain brings down the same sign of charge as that below it which is causing the field. Thus in the earth's normal feld the charge on the earth is negative, and the rain would bring duwn a negative charge leaving the corresponding positive charge above. This would intensify the field. In fact, according to the theory, the rain would always intensify a field; it could under no circumstances weaken, much less reverse, it.

Let us follow the process in some detail. Imagine that the clouds on a given day gradually increase in density. We know from observation that this does not disturb the earth's normal field. Now let rain commence. The drops have a positive charge induced on their lower halves, which is lost by impact with cloud particles and smaller drops; hence the rain will arrive at the ground with a negative charge. This intensifies the field and causes subsequent rain to be more highly charged. And so the process goes on with an ever-increasing field. But observation shows that this practically never occurs. With non-thunderstorm rain it almost always happens that as soon as the rain starts the field is reversed and the potential gradient becomes negative. As the rain cannot reverse the field some other factor must have come into play. What is it? We must pause to consider how the field can be reversed. The field 
can only be reversed when the excess of positive electricity which is normally in the air has been replaced by an excess of negative electricity. We bave just seen that the influence effect still further increases the positive electricity in the air; therefore the effect which reverses the field must remove positive electricity from the air faster than the rain leaves it behind. Elster and Geitel have realized this difficulty, and say "We very much doubt whether the earth's normal field mustalways be considered as the exciting field. (a) Selective absorption on the precipitation particles during and after the condensation, and (b) the breaking of drops in the air as investigated by Simpson, act as electromotive forces. (c) Further, the shifting of electrified cloud masses by wind, and $(d)$ lightning discharges in the later stages, could cause electrical fields which are quite independent of the earth's normal field $" *$.

We can neglect $(d)$ as we are at present considering the initial stages. At the stage we are considering the cloud masses will be positively charged by the influence effect, hence (c) may be neglected. If $(a)$ and $(b)$ are sufficiently efficient to produce rain so highly charged with positive electricity as to overbalance the rain charged negatively by influence, then they should be considered as the chief cause of the electricity of precipitation.

It appears to me useless to explain the general electricity of rain by one process, and then to have to introduce a more powerful effect to explain the large changes in the electrical field which accompany it.

This consideration, which is damaging to the theory with non-thunderstorm rain, becomes more important with thunderstorms. The most marked feature in a thunderstorm is the rapid reversal of the high electrical field. It does not appear helpful to explain the processes at work by an effect which under no circumstances can reverse a field. The mistake made by Elster and Geitel is that they have inverted cause and effect. They make the electrical field the canse of the charge on the rain, while in reality it is the charge on the rain which gives rise to the electrical field.

One could go much more fully into the failure of Elster and Geitel's theory, but enough has been said to prove it unsatisfactory. The theory will die a natural death if it can be shown that there is another which fits the facts better. We will therefore now discuss the alternative theory.

* Elster \& Geitel, Phys. Zeit. xiv. p. 1290 (1913). 
B. The "Breaking Drop" Theory.

This theory is founded on the observed fact that when a drop of water is broken up into smaller drops, the water becomes positively charged and the air negatively charged. If there is any large amount of breaking of drops there is bound to be a large separation of electricity. In thunderstorms, which are known to have associated with them violent ascending currents of air, there is no doubt that the water-drops are much broken and, as shown in the paper in which the theory was formulated *, there is no doubt that all the chief electrical phenomena of thunderstorms can be accounted for by the theory. When the theory was published in 1909 there were not sufficient observations on the electricity of non-thunderstorm rain and snow to test the theory in respect to these. It is proposed now to extend the theory to them.

Non-thunderstorm rain.-For the theory to explain the electrification of rain there must be a certain amount of breaking of drops. The difficulty, however, is that according to experiments made by Leonard $t$, drops of water of less diameter than $4 \mathrm{~mm}$. are not broken by falling through air. As in non-thunderstorm rain the majority of the drops are much smaller than this, it would appear that there would be little or no breaking of drops. That this conclusion is not strictly true can be observed in a simple manner. If one stands during a rain shower in such a position that the falling drops can be seen against a dark background, then after a little practice the following will be noticed. The drops will be seen to be falling in parallel lines inclined from the vertical, the direction being determined by the wind. Suddenly, as a gust of wind comes, the angle of fall will change and the drops will become confused. At this moment a large number of very fine drops will appear. Whether these small drops are formed by the breaking of the drops due to the wind itself, or as a result of collisions, it is impossible to say, but there can be no doubt of the breaking of the drops by one cause or another.

Then again there is the question of one drop overtaking another and colliding with it. Leonard has shown that such collisions are probably rare with real raindrops. At the same time there must be a certain amount of collision through one cause or another. When two drops collide it is very unlikely that they unite and continue as one large drop. On the contrary, they will "splash" against one another and

* Loc. cit.

$\dagger$ Leonard, Met. Ziit. xxxix. p. 257 (1904). 
in all probability break up into smaller drops than either of them was before the collision. It does not appear possible to deny some amount of breaking of drops, the only question is, how much takes place?

Assuming that drops do break, we will now consider what the result of the splashing would be. We will again take the case of the formation of a rain cloud on a day with the normal potential gradient. Until the rain commences to fall there is no separation of electricity in the cloud and the normal potential gradient remains unaffected. The potential gradient indicates a negative charge on the ground, and the corresponding positive charge is in the form of a volume charge in the air above. Now when the rain commences and collisions take place, the rain becomes positively charged and the negative charge remains behind in the cloud or in the air beneath it. Before very long the rain has brought. down sufficient positive electricity to the ground and left sufficient negative charge behind to reverse the normal field Thus during steady rain one would expect positively charged rain and a reversed electrical field, and this is exactly what is found by observation. If the air from the rain area is carried over the surrounding country by the wind, it may have such a large volume charge of negative electricity that it will reverse the field by itself. This accounts for the fact that as a rain shower moves across the country, the normal field is often reversed before the rain actually commences at a station. We see from this that the theory accounts for the facts qualitatively, but is it sufficient quantitatively? The want of accurate measurements makes a definite reply to this question difficult.

Schindelhauer * found that with non-thunderstorm rain (Landregen) 92 per cent. of his observations showed a positive charge, of which 81 per cent. gave a vertical current of between 1 and $5 \times 10^{-15} \mathrm{amp} . / \mathrm{cm} .^{2}$ Baldit $\dagger$ found for the same kind of rain 85 per cent. of positively charged rain, of which 86 per cent. gave a vertical current of between $\cdot 1$ and $10 \times 10^{-15} \mathrm{amp} . / \mathrm{cm} .{ }^{2}$ From these figures it will be safe to say that the average current produced by the descending positively charged rain is about $2 \times 10^{-15} \mathrm{amp} . / \mathrm{cm} .^{2}$ This is equivalent to $6 \times 10^{-6}$ E.S.U. per $\mathrm{cm} .^{2}$ per second. Now the normal charge on the ground, assuming a potential gradient of 100 volts per metre, is $-3 \times 10^{-4}$ E.S.U. per cm. ${ }^{2}$ Thus we see that the potential gradient would be reversed in $\frac{3 \times 10^{-4}}{6 \times 10^{-6}}$ secs. $=50$ secs. Hence the reversal of the field is

* Schindelhauer, Ver, Kon. Preuss. Met. Institut, No. 263, p. 27 (1913). † Baldit, Le Radium, ix. March, 1912. 
easily accounted for by the electricity brought down by the rain.

It is more difficult to determine how much breaking of drops would be necessary to give the charge found on the rain. For this we ought to know the charge on the drops; but so far this is entirely unknown. The next approximation is to know the charge on a c.c. of rain-water. This also is practically unknown for non-thunderstorm rain. From a very few observations Schindelhauer concludes that it is about - 5 E.S.U. per c.c. This, however, is too high a charge, for it would mean that abont 80 per cent. of the "Landregen" he investigated fell at a rate of only $\cdot 4 \mathrm{~mm}$. per hour, which is unlikely. Probably the mean charge on non-thunderstorm rain is about 1 E.S.U. per c.c. Now the best observations made on the electrification produced by breaking drops of water are those of J.J. Nolan*, who found that charges up to $1 \cdot 36$ E.S.U. per c.c. could be given to water by breaking it into very fine spray.

This indicates that if about $1 / 10$ of the rain was broken up once into fine drops the observed charge would be produced. Future observations must decide whether this amount of breaking does occur, at present we can only say that quantitatively the theory is not impossible.

These considerations lead to the conclusion that with nonthunderstorm rain the sign of the charge on the rain and the reversal of the field are explained by the theory, the only outstanding question is whether there is sufficient breaking of drops during light steady rain to give the charges observed.

Snow.-Very few observations on the electricity of snow have been made, the chief being those of the writer in Simla $\dagger$ and those of Schindelhauer in Potsdam $\ddagger$.

At both Simla and Potsdam the snow was sometimes positively and sometimes negatively charged, and on occasion the snow proved to he very highly eharged. In one important respect the results from the two stations were opposite. In Simla the snow brought down a large excess of pusitive electricity, while at Potsdam the excess, also large, was negative.

The chief objection brought against the theory based on the electrification through the breaking of drops has been that it cannot explain the electrification of snow in which there are no drops to break. But there is with solids the exact counterpart of the phenomenon with liquids. When a drop breaks the liquid takes a positive charge and the air a

\footnotetext{
* Nolan, Proc. Roy. Soc. A. xc. pp. $531-543$ (1914).

+ Simpson, Proc. Roy. Soc. A. Ixxxiii. pp. 402-403 (1910).

$\ddagger$ Loe. cit.
} 
negative charge. Now Rudge* has shown that when two solids are rubbed together, the air near them becomes charged and in consequence the sum of the charges left on the solids is the complement of the charge given to the air. In other words, the collision and friction of solids of the same kind produces a charge on the solid and a charge of the opposite sign in the air.

When the collisions are sufficient in number the electrical separation can be very large, and by blowing dust into the air a large separation of electricity can be effected. It is not difficult to imagine that a snow storm is a repetition of Rudge's experiments on an enormous scale in which the snow-flakes take the place of the dust particles. The constant collision and rubbing together of the snow-flakes causes them to be charged and the air to receive the opposite charge. As. the snow falls it leaves the charged air behind it, so producing a separation of electricity which accounts for the observed electrical effect.

Rudge did not make any experiments with snow or ice, therefore his work does not indicate the sign of electricity we might expect on the snow. The following observation made in the Antaretic, however, confirms his general conclusion and gives the sign desired.

On December 6th, 1911, there was a heavy fall of snow. Two days later, when the sky was cloudless, a wind sprang up from the north eausing a very heavy drift of loose snow along the surface. The driven snow did not extend more than four or five feet above the ground. The collector of the potential gradient apparatus was well above the top of the drift. As soon as the wind arose and the drift commenced, the potential gradient was reversed and high negative values were recorded as long as the surface drift continued. This observation showed that the drift snow bad a high positive charge. The drift was blowing over the frozen sea and therefore came into contact with nothing but snow ; hence the charge was produced by the friction of snow on snow.

Returning now to the conditions during snowfall, we have shown how the snow can obtain a positive charge. Assuming an ascending air current (this is necessary for snowfall as for rainfall) the charged air will ascend as the snow descends, so that there will be an accumulation of negative electricity towards the top of the cloud. Snow formed here will start with a negative charge, which, under suitable conditions, it might carry down to the ground ; thus accounting for the negatively charged snow.

The high charges found by Rudge on dust would lead one

* Rudge, Proc. Roy. Soc. A. xe. pp. 256-272 (1914). 
to expect that the electrical effect with snow is very large, probably much larger than can be obtained by splashing water, and this would explain the high charges observed. But a snow-flake is much less suitable than a raindrop for causing a large separation of electricity, for its downward movement relative to the air is very small, hence much of the electricity separated joins up again. This probably accounts for the absence of thunder and lightuing during snowstorms.

In Simla we have much thunder and lightning at the beginning of snowstorms, but so far as my observations go, during the thunder and lightning the snow is accompanied by much small soft hail. The latter, falling through the snow, becomes highly charged by impact, and its rapid rate of fall gives the condition for a large separation of electricity. This no doubt accounts for the large excess of positive charge on the snow investigated at Simla.

It is questionable whether thunder and lightning ever accompany a pure snowstorm. Certainly they do not occur in polar regions, and are very rare during snow in the winter in Europe. More observations will probably prove that violent ascending currents producing soft hail are necessary for thunder and lightning to accompany a snowstorm.

The latter part of this paper may be summarised by stating how each of the results of observation given on pages $1-3$ is accounted for by the theory.

(1), (4), and (8). The process described gives a positive charge to the precipitation and a negative charge to the air, thus acconnting for the positively charged precipitation. The air carrying its negative charge may get removed from the place of origin, and then precipitation formed in it will start with a negative charge. If this falls to the ground without becoming charged positively, it will appear as negatively charged precipitation.

(2) and (5). The chief factor at work gives rise to a positive'charge on the precipitation and a negative charge on the air. As the precipitation falls to the ground, while the air tends to prevent the negative charge reaching the ground, the precipitation as a whole will be positively charged.

$(3),(7)$, and (11). The changes in the potential gradient result directly from the large separation of electricity, and from the fact that the charge carried to the ground by the precipitation completely masks the small permanent charge normally on the ground.

(2) and (b). During quiet non-thunderstorm rainfall there is not so much breaking of drops as in thunderstorms with their violent ascending currents, hence the charges are less. At the same time the conditions are more suitable for 
the complete separation of the electricity, hence the ratio of positive to negative electricity is greater.

(10) The separation of electricity produced by the impact and friction of solids is probably greater than that produced by the splashing of drops, hence very large charges on snow may be expected.

Simla, March 1915.

Appendix.

Observations on the electricity of precipitation.

\begin{tabular}{|c|c|c|}
\hline Place. & Observers. & Publications. \\
\hline $\begin{array}{l}\text { Wolfenbeütel } \\
\text { (Brunswick). }\end{array}$ & Elster \& Geitel. & $\begin{array}{l}\text { Wien. Ber. xcix. p. } 421(189(1) \\
\text { Terr. Magn. iv. p. } 15(1899) \text {. }\end{array}$ \\
\hline Göttingen. & Gerdien. & $\begin{array}{l}\text { Münch. Ber. xxxiii. p. } 367 \text { (1903). } \\
\text { Phys. Zeit. ir. p. } 837 \text { (1903). }\end{array}$ \\
\hline Vienna. & Weiss. & $\begin{array}{l}\text { Wien. Ber. cxv. Abt. ii a. p. } 1299 \\
\text { (1906). }\end{array}$ \\
\hline Porto Rico. & Kohlrausch. & $\begin{array}{l}\text { Wien. Ber. cxviii. Abt. ii } \alpha . \text { p. } 25 \\
(1909) \text {. }\end{array}$ \\
\hline Simla (India). & Simpson. & $\begin{array}{l}\text { Phil. Trans. A. ccix. p. } 379(1909) \text {. } \\
\text { Proc. Roy. Suc. A. Ixxxiii. p. } 394 \\
\text { (1910). } \\
\text { Full details of observations given in } \\
\text { India Met. Memoirs, vol. yx. } \\
\text { pt. 8. }\end{array}$ \\
\hline Potsdam. & $\begin{array}{l}\text { K. Käbler. } \\
\text { F. Sebindelhauer. }\end{array}$ & $\begin{array}{l}\text { Phys. Zeit. ix. p. } 258(1908) \text {. } \\
\text { Veroff d. k. Preuss. Met. Inst. } \\
\text { No. } 213(1909) . \\
\text { Do. No. 263 (1913). }\end{array}$ \\
\hline Graz. & Benndorf. & $\begin{array}{l}\text { Wien. Ber, cxix. p. } 89 \text { (1910). } \\
\text { Sitz. Ber. K.B. dkad. d. Wiss. } \\
\text { München, p. } 402(1912) .\end{array}$ \\
\hline Puy-en-Velay. & Baldit. & $\begin{array}{l}\text { Le Tradium, viii. April } 1911 . \\
\text { Do. ix. March } 1912 .\end{array}$ \\
\hline Buenos Aires. & Berndt. & $\begin{array}{l}\text { Phys. Zeit. xiii. p. } 151(1912) \text {. } \\
\text { Veroff d. Dentsch. Wiss. Vereins in } \\
\text { Buenos Aires, No. } 3(\mathbf{1 9 1 3}) \text {. }\end{array}$ \\
\hline Dublin. & MeClelland \& Nolan. & $\begin{array}{l}\text { Roy. Irish Acad. Proc. xxix. p. } 81 \\
\text { (1912). } \\
\text { Do. xxx. p. } 61 \text { (1912). }\end{array}$ \\
\hline
\end{tabular}

